\title{
Genetic characterization of an H5N6 avian influenza virus with multiple origins from a chicken in southern China, October 2019
}

Feng Wen ${ }^{1^{*}+} \mathbb{D}$, Jing Yang ${ }^{1+}$, Jinyue Guo ${ }^{1}$, Congying Wang ${ }^{1}$, Qing Cheng ${ }^{1}$, Zheng Tang ${ }^{1}$, Kaijian Luo ${ }^{3}$, Sheng Yuan ${ }^{1}$, Shujian Huang ${ }^{1}$ and Yong $\mathrm{Li}^{2^{*}}$

\begin{abstract}
Background: Highly pathogenic avian influenza viruses (HPAIVs) of H5 subtype pose a great threat to the poultry industry and human health. In recent years, H5N6 subtype has rapidly replaced H5N1 as the most predominate HPAIV subtype circulating in domestic poultry in China. In this study, we describe the genetic and phylogenetic characteristics of a prevalent H5N6 strain in Guangdong, China.

Results: Nucleotide sequencing identified a H5N6 subtype HPAIV, designated as A/chicken/Dongguan/1101/2019 (DG/19), with a multibasic cleavage site in the hemagglutinin (HA). Phylogenetic analysis revealed DG/19 was a reassortant of H5N1, H5N2, H5N8, and H6N6 subtypes of avian influenza viruses. A number of mammalian adaptive markers such as D36N in the HA were identified.

Conclusions: Our results showed that HPAIV H5N6 strains still emerge in well-managed groups of chicken farms. Considering the increasing prevalence of H5N6 HPAIV, and the fact that H5N6 HPAIVs are well adapted to migratory birds, an enhanced surveillance for the East Asian-Australasian flyway should be undertaken to prevent potential threats to the poultry industry and human health.
\end{abstract}

Keywords: Avian influenza viruses, H5N6, HPAIV, East Asian-Australasian flyway

\section{Background}

Avian influenza viruses (AIVs) are a group of enveloped viruses characterized with an eight-segmented, singlestranded, negative-sense RNA genome [1]. AIVs can be categorized into subtypes based on the antigenicity of two surface glycoproteins, hemagglutinin (HA) and neuraminidase (NA). To date, $16 \mathrm{HA}$ subtypes and 9 NA subtypes of AIVs are reported [2]. In addition, according to the severity of disease in chickens caused by

\footnotetext{
* Correspondence: wenf@fosu.edu.cn; liyong2912@163.com

${ }^{\dagger}$ Feng Wen and Jing Yang contributed equally to this work.

'College of Life Science and Engineering, Foshan University, Foshan 528231, Guangdong, China

${ }^{2}$ College of Animal Science and Technology, Jiangxi Agricultural University, Nanchang 330045, Jiangxi, China

Full list of author information is available at the end of the article
}

AIVs, AIVs are classified into highly pathogenic avian influenza viruses (HPAIVs) and low pathogenic avian influenza viruses (LPAIVs) [3]. HPAIVs, including subtypes of $\mathrm{H} 5$ and $\mathrm{H} 7$, which code for a furin-sensitive multibasic cleavage site (-RRKKR-) in the HA $[4,5]$, are capable of inducing systemic infections in multiple tissues and causing dramatic economic losses in the poultry industry.

In 1996, the first HPAIVs of H5N1 subtype (A/goose/ Guangdong/1/1996 (H5N1)) was isolated from an outbreak affecting domestic geese in Foshan city, Guangdong province, China. A year later, the first human clinical respiratory case of $\mathrm{H} 5 \mathrm{~N} 1$ was reported in Hong Kong, China [6, 7]. Since then, the H5N1 virus has spread across to spread to Southeast Asia, the Middle

(c) The Author(s). 2021 Open Access This article is licensed under a Creative Commons Attribution 4.0 International License, which permits use, sharing, adaptation, distribution and reproduction in any medium or format, as long as you give appropriate credit to the original author(s) and the source, provide a link to the Creative Commons licence, and indicate if changes were made. The images or other third party material in this article are included in the article's Creative Commons licence, unless indicated otherwise in a credit line to the material. If material is not included in the article's Creative Commons licence and your intended use is not permitted by statutory regulation or exceeds the permitted use, you will need to obtain permission directly from the copyright holder. To view a copy of this licence, visit http://creativecommons.org/licenses/by/4.0/. The Creative Commons Public Domain Dedication waiver (http://creativecommons.org/publicdomain/zero/1.0/) applies to the data made available in this article, unless otherwise stated in a credit line to the data. 
East, Africa, and Europe, undergoing a number of genetic reassortments [8-11]. In 2014, the first H5N6 strain was isolated from backyard poultry flocks in Guangdong province, China [12]. Subsequently, HPAIV H5N6 became one of the major subtypes of the $\mathrm{H} 5$ clade 2.3.4.4. To date, since the first case of human infection with HPAIV H5N6 in Sichuan province in April 2014 [13], more than 23 cases of infection and 9 deaths were recorded (www.who.int/influenza/human_animal_ interface). During the past several years, the HPAIV H5N6 subtype has continuously evolved and has replaced H5N1 as one of the main HPAIV subtypes in domestic poultry in China [13-16]. A more recent study suggested that the positive rate of H5N6 in live poultry markets (LPM) is $7.87 \%$, which became the second most dominant subtype currently circulating in LPMs in China [16]. Moreover, human infection of HPAIV H5N6 subtype even had a higher mortality than H5N1 subtype based on the clinical statistical data thus far [17]. Therefore, the HPAIV H5N6 subtype contributes as a major threat to domestic poultry and human health.

In this study, we report the genetic and phylogenetic characteristics of a HPAIV H5N6 strain isolated (October 2019) from chicken farms in Dongguan, Guangdong province, China.

\section{Results}

Primers targeting the conserved region of $\mathrm{M}$ segment were used to detect the influenza A virus in the liver and spleen of chickens (Supplementary Figure 1) and a band of $226 \mathrm{bp}$ was observed (Supplementary Figure 2A). All 8 viral segments (PB2, 2280 bp; PB1, 2280 bp; PA, 2152 bp; HA, 1701 bp; NP, 1497 bp; NA, 1380 bp; M, 982 bp; NS bp, and $823 \mathrm{bp}$ ) (Supplementary Figure $2 \mathrm{~B}$ ) were successfully amplified and sequenced by cloning to the pMD 18$\mathrm{T}$ vector. The results revealed that the AIV in this study belongs to a H5N6 subtype, which was designated as A/ chicken/Dongguan/1101/2019 (H5N6)(DG/19). DG/19 contained six basic amino acid residues at HA cleavage site (RERRRKR $\downarrow$ GLF) (Table 1), which suggested a high pathogenicity phenotype in chickens.

The nucleotide sequences of DG/19 were aligned with the reference strains deposited in Global Initiative on Sharing Avian Influenza Data (GISAID, www.gisaid.org) and GeneBank by ClustalW. Subsequently, the phylogenetic trees for HA (Fig. 1a) and NA (Fig. 1b) genes were constructed by the maximum likelihood method. Our phylogenetic results showed that the DG/19 HA belong to clade 2.3.4.4. A further comparison with the reference sequence of the sub-clades of 2.3.4.4 suggested DG/19 belongs to the 2.3.4.4 $\mathrm{h}$ subclade. The internal genes of DG/ 19 had high identity with strains isolated from ducks in 2017-2018 in Hunan by a recent study [16]. The HA gene has the highest nucleic acid homology with $\mathrm{A} /$ duck/Hunan/1.12_YYGK 72H3-OC/2018(H5N6) (98.35\%). Furthermore, it is worth noting that the NA gene of DG/19 has high nucleic acid homology with A/muscovy duck/Japan/AQ-HE30-77C2/ 2018 (H5N6) (97.89\%). The sequence alignment suggested DG/19 had Q142H, N89S, D36N, D193N mutations in the HA compared to the closest reference strain A/duck/ Hunan/1.12_YYGK72H3-OC/2018 (H5N6).

We further analyzed the glycosylation sites by NetNGlyc 1.0 server, the data revealed that the DG/19 has eight potential glycosylation sites at positions $27,39,70$, 140, 180, 301, 497, and 556 within the HA protein (Fig. 2a). The glycosylation site at the 158 site has been lost due to the T160A substitution. Meanwhile, a total of five potential glycosylation sites at positions $57,60,65,141$, and 196 within the NA protein were identified (Fig. 2b). In addition, the 3D structure model of HA of DG/19 was predicted by the SWISS-MODEL server and the predicted local similarity to the target with the highest sequence similarity (6PCX) was shown in Fig. 2c.

Further analysis of internal genes revealed that the PB2 gene segment had high identity with those recent

Table 1 Molecular characteristics of H5 isolates associated with pathogenicity

\begin{tabular}{|c|c|c|c|c|c|c|c|c|c|c|c|c|}
\hline \multirow[t]{3}{*}{ Virus } & \multirow[t]{3}{*}{ Subtype } & \multirow[t]{3}{*}{ Clade } & \multirow[t]{3}{*}{ Pathotype } & \multicolumn{3}{|l|}{ HA } & \multicolumn{3}{|l|}{ NA } & \multicolumn{2}{|c|}{ PB2 } & \multirow{3}{*}{$\begin{array}{l}\text { PB1 } \\
473\end{array}$} \\
\hline & & & & \multirow{2}{*}{$\begin{array}{l}\text { Cleavage } \\
\text { site }\end{array}$} & \multicolumn{2}{|l|}{ RBS } & \multirow{2}{*}{$\begin{array}{l}\text { stalk } \\
\text { deletion }\end{array}$} & \multirow[t]{2}{*}{274} & \multirow[t]{2}{*}{294} & \multirow[t]{2}{*}{23} & \multirow[t]{2}{*}{627} & \\
\hline & & & & & $\overline{186}$ & $\begin{array}{l}226- \\
228\end{array}$ & & & & & & \\
\hline A/Anhui/1/2005 & $\mathrm{H} 5 \mathrm{~N} 1$ & 2.3 .4 & $\mathrm{HPAl}$ & RERRRKRGLF & $\mathrm{N}$ & QSG & YES & $\mathrm{H}$ & $\mathrm{N}$ & $\mathrm{T}$ & $E$ & V \\
\hline A/Hunan/1/2009 & H5N1 & 2.3.4.1 & HPAl & RERRRKRGLF & $\mathrm{N}$ & QSG & YES & $\mathrm{H}$ & $\mathrm{N}$ & $\mathrm{T}$ & $E$ & V \\
\hline A/goose/Yunnan/6193/2006 & H5N1 & 2.3.4.2 & HPAl & RERRRKRGLF & $\mathrm{N}$ & QSG & YES & $\mathrm{H}$ & $\mathrm{N}$ & $\mathrm{T}$ & $E$ & V \\
\hline A/avian/Hong_Kong/2372/2007 & H5N1 & 2.3.4.3 & HPAl & RERRRKRGLF & $\mathrm{N}$ & QSG & YES & $\mathrm{H}$ & $\mathrm{N}$ & $\mathrm{T}$ & $E$ & V \\
\hline A/duck/Hunan/2.06_YYGK78J3-OC/2018 & H5N6 & 2.3.4.4 & HPAl & RERRRKRGLF & $\mathrm{N}$ & QRG & NO & $\mathrm{H}$ & $\mathrm{N}$ & $\mathrm{T}$ & $E$ & V \\
\hline A/chicken/Dongguan/1101/2019 & H5N6 & 2.3.4.4 & HPAl & RERRRKRGLF & $\mathrm{N}$ & QRG & YES & $\mathrm{H}$ & $\mathrm{N}$ & $\mathrm{T}$ & $E$ & V \\
\hline $\begin{array}{l}\text { A/muscovy duck/Japan/AQ-HE30-77C2/ } \\
2018\end{array}$ & H5N6 & 2.3.4.4 & HPAl & RERRRKRGLF & $\mathrm{N}$ & QRG & YES & $\mathrm{H}$ & N & $T$ & $E$ & V \\
\hline
\end{tabular}



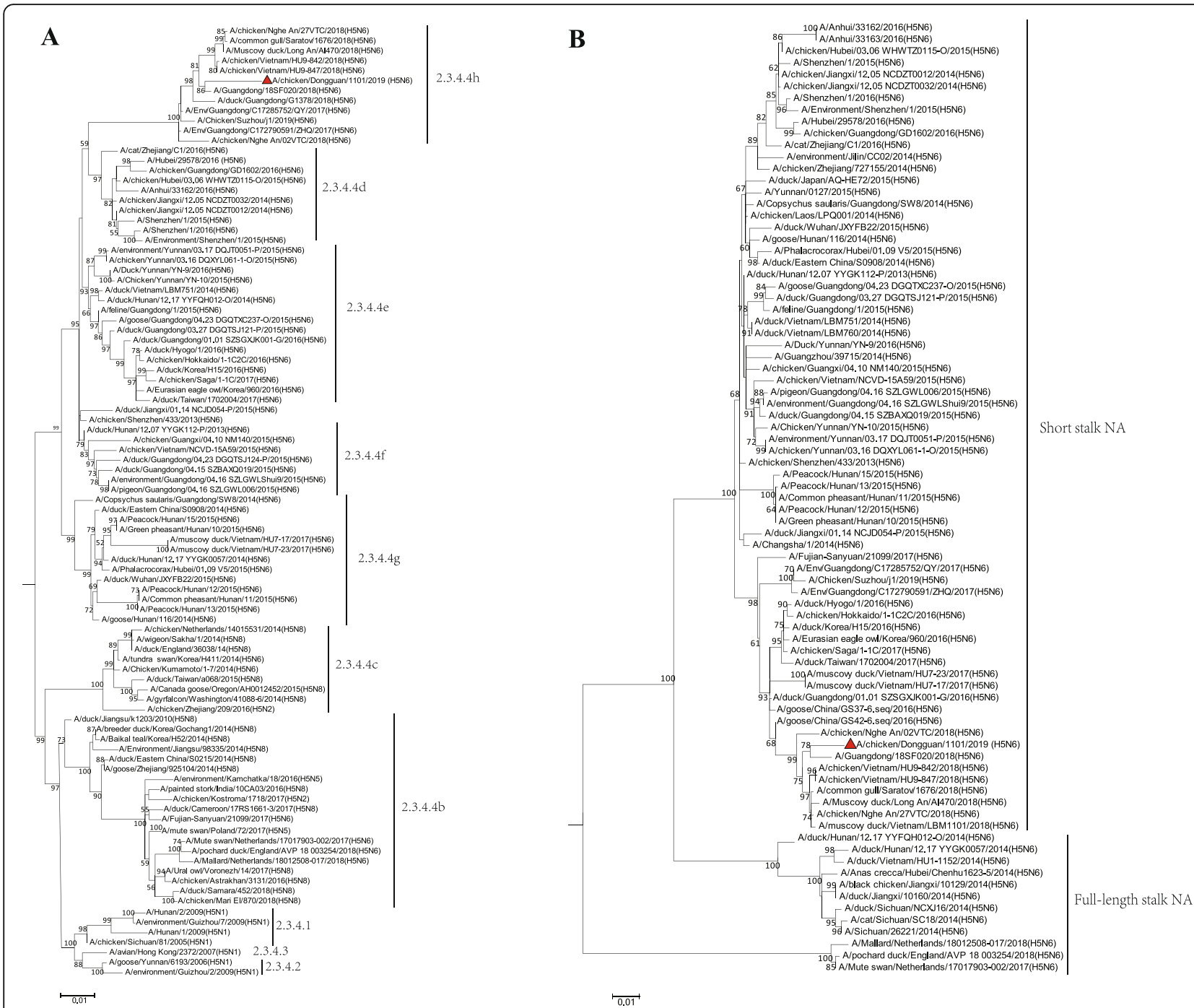

Fig. 1 The maximum likelihood phylogenetic trees for the hemagglutinin (HA) and neuraminidase (NA) genes of the A/chicken/Dongguan/1101/ 2019 (H5N6)(DG/19) in this study. Phylogeny analysis was performed using the maximum likelihood method with 1000 bootstrap replicates in MEGA 7. The DG/19 in this study is indicated with red triangles. a Phylogenetic tree of HA gene for DG/19 suggested it belongs to clade 2.3.4.4. b Phylogenetic tree of NA gene for DG/19 suggested it belongs to Eurasian lineage. The isolates described in this study was marked with red triangle

H5N6 isolates in China, which was likely originated from H6N6 AIVs as the NA did. The PA and NS gene segments suggested a H5N8 origin. In addition, the M gene segment of DG/19 showed the highest similarity to the $\mathrm{M}$ gene of H5N2 AIVs. The phylogenetic trees for internal genes were shown in Supplementary Figure 3. These results suggest DG/19 is a reassortant of H5N1, H5N2, H5N8, and H6N6 AIVs (Fig. 2d), which might happen through the East Asian-Australasian flyway [18].

\section{Discussion}

Southern China has been considered as a hot spot for the generation of novel AIVs. In this study, we reported the genetic characterization of a recent H5N6 HPAIV strain isolated from chickens in southern China. In addition, novel mutations such as D36N, which is one of the six common amino acid substitutions of $\mathrm{H} 2$ subtype AIV from mallards to swine [19], are emerging from H5N6 HPAIVs. These observations indicate a potential mammalian adaptation of H5N6 AIV. Fortunately, our results showed that DG/19 possessed 226Q and 228G (H3 numbering) in the HA, which suggested a typical avian receptor preference and were consistent with previous studies [16]. However, DG/19 has 222Q and 227R in the HA, which has been shown to facilitate virus binding to fucosylated sialosides [20]. Sialyl Lewis ${ }^{X}$ 


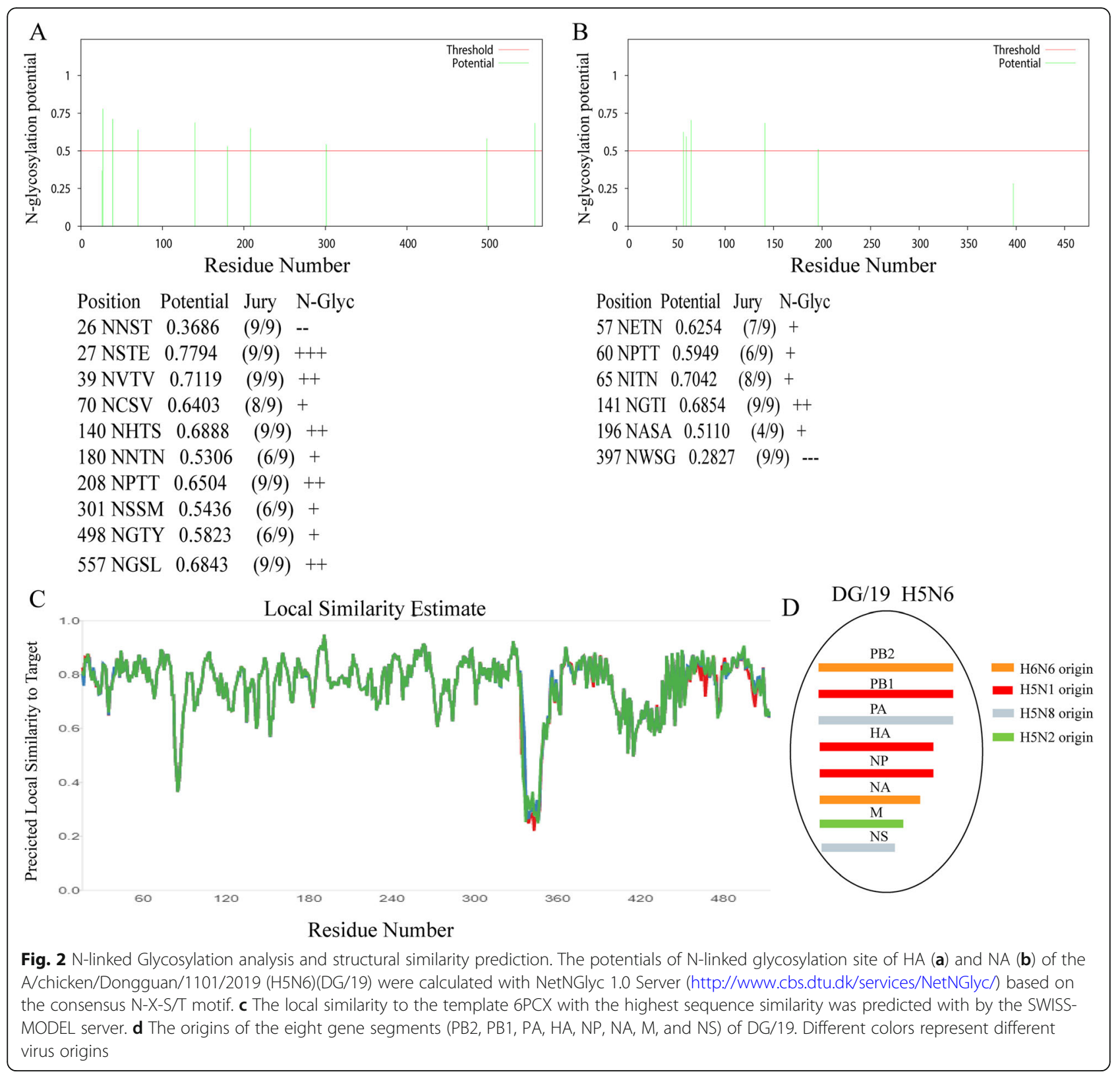

glycans (Neu5Gc $\alpha 2-3 \mathrm{Gal} \beta 1-4$ (Fuc $\alpha 1-3)$ GlcNAc $\beta$ ) were shown on the respiratory track of terrestrial birds but not on the intestinal tract of ducks [21, 22]. The 222Q and 227R on HA of DG/19 suggested that H5N6 AIV has been well adapted to terrestrial birds, which made H5N6 AIV easier to adapt to mammalian hosts. The $226 \mathrm{Q}$ and loss of the glycosylation site at 158 suggested DG/19 prefers avian-type receptors $[13,16]$.

In addition, a number of novel mutations in the HA of H5N6 HPAIV were identified, including Q142H, N89S, and D193N. It has been suggested that the D193N mutation of H10N7 virus promoted virus binding to $\alpha 2,6$ linked sialic acid receptors without an impair of binding to $\alpha 2,3$-linked sialic acid receptors [23]. However, the biological effects of those mutations need further investigation.

The NA protein of DG/19 has a 11-aa stalk deletion at residues 59-69, which has been shown to enhance virulence in mammals [24]. Moreover, the L473V substitution was observed in PB1 of DG/19, which was associated with the improved replication of AIV in mammalian cells [25].

\section{Conclusion}

In this study, we report the genetic characteristics of a recent HPAI H5N6 (DG/19) strain from chickens in southern China. Our results revealed HPAIV H5N6 strain circulating in south China is potentially a 
reassortment between $\mathrm{H} 5 \mathrm{~N} 1, \mathrm{H} 5 \mathrm{~N} 2, \mathrm{H} 5 \mathrm{~N} 8$, and $\mathrm{H} 6 \mathrm{~N} 6$ AIVs, highlighting the importance of continuous surveillance of AIVs through the East Asian-Australasian flyway. Further studies are needed to investigate the biological role of those novel mutations identified in this study.

\section{Methods}

Surveillance of avian influenza virus in domestic poultry The routine surveillance of AIV was performed in domestic poultry in Guangdong, China. In October 2019, an outbreak of AIV was reported in a chicken farm in Dongguan, Guangdong province. The liver and spleen samples collected from chickens were homogenized $3 \mathrm{cy}-$ cles by Precellys Evolution Super Homogenizer (France) at $6000 \mathrm{rpm}$ for $15 \mathrm{~s}$. The viral RNA extraction and reverse transcription was performed as previously described [18, 26]. Briefly, viral RNA was extracted by Body Fluid Viral DNA/RNA Miniprep kit (Axygen, China) according to the manufacturer's instructions. The Maxima H Minus First Strand cDNA Synthesis Kit (Thermo Fisher Scientific, USA) with a Uni12 primer (5'-AGCGAAAGCAGG-3') was used for reverse transcription. The present of AIV was confirmed by RT-PCR with a universal primer (M7F: 5' -CTTCTAACCGAGGT CGAAACG-3', M232R: 5'-GTCTACGCTGCAGTCC TCGCT-3') targeting the conserved region of $M$ segment.

\section{Virus sequencing}

All 8 gene segments of DG/19 were successfully amplified by Phusion Hot Start II High-Fidelity PCR Master Mix (Thermo Fisher Scientific, USA) with a set of universal primers described by Hoffmann et al. [27]. The temperature cycle parameters were $98^{\circ} \mathrm{C}$ for $30 \mathrm{~s}$, followed by 35 cycles of $98^{\circ} \mathrm{C}$ for $10 \mathrm{~s}, 53^{\circ} \mathrm{C}$ for $30 \mathrm{~s}$, and $72{ }^{\circ} \mathrm{C}$ for $2 \mathrm{~min}$, with a final extension at $72{ }^{\circ} \mathrm{C}$ for 10 min. The PCR products were purified by using Gene JET Extraction Kit (Thermo Fisher Scientific, USA) according to the manufacturer's instructions. Subsequently, the purified PCR segments were incubated for 15 min at $72{ }^{\circ} \mathrm{C}$ with Premix Taq (Takara, Japan), then subcloned into the pMD-18 $\mathrm{T}$ vector and sequenced by Sanger sequencing.

\section{Phylogenetic analysis}

A total of 95 representative H5N6 strains from Global Initiative on Sharing Avian Influenza Data (GISAID, www.gisaid.org) or Influenza research database (IRD, www.fludb.org) were selected for molecular evolutionary analyses. The full length of HA (1701 bp) and NA (1380 bp) genes were aligned by ClustalW and phylogenetically clustered by maximum likelihood method with 1000 bootstrap replicates in MEGA7.

\section{Structural and N-linked glycosylation site prediction} The 3D structure model of HA of DG/19 was analyzed by the SWISS-MODEL server (https://swissmodel. expasy.org/) [28]. In brief, the HA sequence of DG/19 was blasted through the SWISS-MODEL library and the template 6PCX with the highest sequence similarity was selected for the model building. In addition, the potential of N-linked glycosylation sites based on the consensus $\mathrm{N}-\mathrm{X}-\mathrm{S} / \mathrm{T}$ motif was calculated as previously described [26].

\section{Abbreviations}

AIVs: Avian influenza viruses; HA: Hemagglutinin; NA: Neuraminidase; HPAI Vs: Highly pathogenic avian influenza viruses; LPAIVs: Low pathogenic avian influenza viruses; GISAID: Global Initiative on Sharing Avian Influenza Data; DG/19: A/chicken/Dongguan/1101/2019 (H5N6); LPMs: Live poultry markets

\section{Supplementary Information}

The online version contains supplementary material available at https://doi. org/10.1186/s12917-021-02903-z.

Additional file 1: Figure S1. Clinical pictures of chickens in this study. Additional file 2: Figure S2. The amplification of conserved $\mathrm{M}$ gene segments (A) and full genome of A/chicken/Dongguan/1101/2019 (DG/ 19).

Additional file 3: Figure S3. The maximum likelihood phylogenetic trees for the PB2(a), PB1(b), PA(c), NP(d), M(e), and NS(f) gene segments of $A /$ chicken/Dongguan/1101/2019 (DG/19). The virus detected in this study was indicated in red star. The scale bars represent the number of substitutions per nucleotide.

\section{Acknowledgments}

We also thank all researchers who shared AIV genome sequences in GISAID, IRD, and GenBank.

\section{Authors' contributions}

F.W and Y. L conceived and designed this study; F. W, J. Y, JY. G, CY. W, Q. C, Z. T KJ. L, S. Y, and SJ. H performed the experiments and data analysis. F. W and J. $Y$ wrote the initial draft of the manuscript. F. W and $Y$. $L$ revised the manuscript. All authors have read and approved the final manuscript.

\section{Funding}

This study was supported by National Key Research and Development Project (Grant No.2017YFD0500800); National Natural Science Foundation of China (Grant No. 32002320); Natural Science Foundation of Guangdong Province, China (Grant No. 2020A1515010116); Medical Scientific Research Foundation of Guangdong Province, China (Grant No. A2020083); The funders of this study had no role in the design, execution, interpretation, or writing of the study.

\section{Availability of data and materials}

The viral sequences obtained in this study are deposited in GenBank under the accession numbers: MW314745, MW314746, MW314795, MW314796, MW314797, MW314798, MW314799, and MW320522.

\section{Declarations}

Ethics approval and consent to participate

This study was approved by the Research Ethics Committee of the College of Life Science and Engineering, Foshan University. Written informed consent was obtained from all owners whose animals were used in the study.

Consent for publication

Not applicable. 


\section{Competing interests}

The authors declare that they have no competing interests.

\section{Author details}

${ }^{1}$ College of Life Science and Engineering, Foshan University, Foshan 528231, Guangdong, China. ${ }^{2}$ College of Animal Science and Technology, Jiangxi Agricultural University, Nanchang 330045, Jiangxi, China. ${ }^{3}$ College of Veterinary Medicine, South China Agricultural University, Guangzhou 510642, Guangdong, China.

Received: 7 December 2020 Accepted: 17 May 2021

Published online: 28 May 2021

\section{References}

1. Bouvier NM, Palese P. The biology of influenza viruses. Vaccine. 2008; 26(Suppl 4):D49-53.

2. Fouchier RA, Munster V, Wallensten A, Bestebroer TM, Herfst S, Smith D, et al. Characterization of a novel influenza a virus hemagglutinin subtype (H16) obtained from black-headed gulls. J Virol. 2005;79(5):2814-22.

3. Swayne DE, Suarez DL. Highly pathogenic avian influenza. Rev Sci Tech. 2000;19(2):463-82.

4. Bosch FX, Garten W, Klenk HD, Rott R. Proteolytic cleavage of influenza virus hemagglutinins: primary structure of the connecting peptide between HA1 and HA2 determines proteolytic cleavability and pathogenicity of avian influenza viruses. Virology. 1981;113(2):725-35.

5. Steiner DF, Smeekens SP, Ohagi S, Chan SJ. The new enzymology of precursor processing endoproteases. J Biol Chem. 1992;267(33):23435-8.

6. Centers for Disease C. Prevention: isolation of avian influenza $A(\mathrm{H} 5 \mathrm{~N} 1)$ viruses from humans--Hong Kong, May-December 1997. MMWR Morb Mortal Wkly Rep. 1997;46(50):1204-7.

7. Chan PK. A review on human influenza a H5N1 infections in Hong Kong. Sci China C Life Sci. 2009;52(5):412-8.

8. Duan L, Bahl J, Smith GJ, Wang J, Vijaykrishna D, Zhang L, et al. The development and genetic diversity of H5N1 influenza virus in China, 19962006. Virology. 2008;380(2):243-54.

9. Chen H, Deng G, Li Z, Tian G, Li Y, Jiao P, et al. The evolution of H5N1 influenza viruses in ducks in southern China. Proc Natl Acad Sci U S A. 2004; 101(28):10452-7.

10. Guan Y, Peiris JS, Lipatov AS, Ellis TM, Dyrting KC, Krauss S, et al. Emergence of multiple genotypes of H5N1 avian influenza viruses in Hong Kong SAR. Proc Natl Acad Sci U S A. 2002;99(13):8950-5.

11. Li KS, Guan Y, Wang J, Smith GJ, Xu KM, Duan L, et al. Genesis of a highly pathogenic and potentially pandemic H5N1 influenza virus in eastern Asia. Nature. 2004;430(6996):209-13.

12. Shen $H$, Wu $B$, Chen $Y, B i$, Xie $Q$. Influenza a(H5N6) virus reassortant, southern China, 2014. Emerg Infect Dis. 2015;21(7):1261-2.

13. Bi Y, Chen Q, Wang Q, Chen J, Jin T, Wong G, et al. Genesis, evolution and prevalence of H5N6 avian influenza viruses in China. Cell Host Microbe. 2016;20(6):810-21.

14. Lee DH, Bertran K, Kwon JH, Swayne DE. Evolution, global spread, and pathogenicity of highly pathogenic avian influenza H5Nx clade 2.3.4.4. J Vet Sci. 2017;18(S1):269-80.

15. Poen MJ, Venkatesh D, Bestebroer TM, Vuong O, Scheuer RD, Oude Munnink BB, et al. Co-circulation of genetically distinct highly pathogenic avian influenza A clade 2.3.4.4 (H5N6) viruses in wild waterfowl and poultry in Europe and East Asia, 2017-18. Virus Evol. 2019:5(1):vez004.

16. Bi Y, Li J, Li S, Fu G, Jin T, Zhang C, et al. Dominant subtype switch in avian influenza viruses during 2016-2019 in China. Nat Commun. 2020;11(1):5909.

17. Bi Y, Tan S, Yang Y, Wong G, Zhao M, Zhang Q, et al. Clinical and immunological characteristics of human infections with H5N6 avian influenza virus. Clin Infect Dis. 2019;68(7):1100-9.

18. Yang J, Li Y, Guo J, Luo K, Yu H, Chen Y, et al. Genetic characterization of an H5N6 avian influenza virus from chickens in Guangdong, China. J Inf Secur. 2020;82(3):414.

19. Ma W, Vincent AL, Gramer MR, Brockwell CB, Lager KM, Janke BH, et al. Identification of H2N3 influenza a viruses from swine in the United States. Proc Natl Acad Sci U S A. 2007;104(52):20949-54.

20. Guo H, de Vries E, McBride R, Dekkers J, Peng W, Bouwman KM, et al. Highly pathogenic influenza a(H5Nx) viruses with altered $\mathrm{H} 5$ receptor-binding specificity. Emerg Infect Dis. 2017;23(2):220-31.
21. Wen F, Blackmon S, Olivier AK, Li L, Guan M, Sun H, et al. Mutation W222L at the receptor binding site of hemagglutinin could facilitate viral adaption from equine influenza A(H3N8) virus to dogs. J Virol. 2018;92:8.

22. Hiono $\mathrm{T}$, Okamatsu M, Igarashi M, McBride $\mathrm{R}$, de Vries RP, Peng W, et al. Amino acid residues at positions 222 and 227 of the hemagglutinin together with the neuraminidase determine binding of $\mathrm{H} 5$ avian influenza viruses to sialyl Lewis X. Arch Virol. 2016;161(2):307-16.

23. Sutton TC, Lamirande EW, Czako R, Subbarao K. Evaluation of the biological properties and cross-reactive antibody response to $\mathrm{H} 10$ influenza viruses in ferrets. J Virol. 2017;91:19.

24. Matsuoka Y, Swayne DE, Thomas C, Rameix-Welti MA, Naffakh N, Warnes C, et al. Neuraminidase stalk length and additional glycosylation of the hemagglutinin influence the virulence of influenza H5N1 viruses for mice. J Virol. 2009;83(9):4704-8.

25. Yamaji R, Saad MD, Davis CT, Swayne DE, Wang D, Wong FYK, et al. Pandemic potential of highly pathogenic avian influenza clade 2.3.4.4 A(H5) viruses. Rev Med Virol. 2020;30(3):e2099.

26. Wen F, Li W, Guo J, Yang J, Zhang X, Mei K, et al. Genetic characterization of a novel genotype H9N2 avian influenza virus from chicken in South China. J Inf Secur. 2020;81(5):816-46.

27. Hoffmann E, Stech J, Guan Y, Webster RG, Perez DR. Universal primer set for the full-length amplification of all influenza a viruses. Arch Virol. 2001; 146(12):2275-89.

28. Waterhouse A, Bertoni M, Bienert S, Studer G, Tauriello G, Gumienny R, et al. SWISS-MODEL: homology modelling of protein structures and complexes. Nucleic Acids Res. 2018;46(W1):W296-303.

\section{Publisher's Note}

Springer Nature remains neutral with regard to jurisdictional claims in published maps and institutional affiliations.

Ready to submit your research? Choose BMC and benefit from:

- fast, convenient online submission

- thorough peer review by experienced researchers in your field

- rapid publication on acceptance

- support for research data, including large and complex data types

- gold Open Access which fosters wider collaboration and increased citations

- maximum visibility for your research: over $100 \mathrm{M}$ website views per year

At BMC, research is always in progress.

Learn more biomedcentral.com/submissions 